\title{
BMJ Open Assessing risk of self-harm in acute paediatric settings: a multicentre exploratory evaluation of the CYP-MH SAPhE instrument
}

\author{
Joseph C Manning (D , , ${ }^{1,2}$ Tim Carter, ${ }^{1}$ Gemma Walker, ${ }^{2}$ Jane Coad, ${ }^{1,3}$ \\ Aimee Aubeeluck, ${ }^{4}$ The CYP-MH SAT Study Group
}

To cite: Manning JC, Carter T, Walker G, et al. Assessing risk of self-harm in acute paediatric settings: a multicentre exploratory evaluation of the CYP-MH SAPhE instrument. BMJ Open 2021;11:e043762. doi:10.1136/ bmjopen-2020-043762

- Prepublication history for this paper is available online. To view these files, please visit the journal online (http://dx.doi. org/10.1136/bmjopen-2020043762).

Part of this paper was presented as a conference abstract at the Young Persons Health Special Interests Group Section of the Royal College of Paediatrics and Child Health Conference 2019, with the abstract published: Manning J, Carter T, Aubeeluck A, et al G597 Psychometric evaluation of a novel self-harm assessment tool for use in acute paediatric settings Archives of Disease in Childhood 2019;104:A241.

Received 13 August 2020 Accepted 18 May 2021

\section{Check for updates}

(C) Author(s) (or their employer(s)) 2021. Re-use permitted under CC BY-NC. No commercial re-use. See rights and permissions. Published by BMJ.

For numbered affiliations see end of article.

\section{Correspondence to} Dr Joseph C Manning; joseph.manning@nottingham. ac.uk

\section{ABSTRACT}

Objective To psychometrically assess the Children and Young People-Mental Health Self-harm Assessment in Paediatric healthcare Environments (CYP-MH SAPhE) instrument for the identification of immediate risk of selfharm in CYP, aged 10-19 years, in acute paediatric wards or emergency departments.

Design The CYP-MH SAPhE Instrument was developed through a robust scoping review and Delphi consensus with 30 clinicians/topic experts. To evaluate the psychometric properties, a multicentre exploratory study was conducted.

Setting Three acute hospitals in the UK.

Participants 163 CYP presenting at acute hospital settings with primary mental health (cases) or physical health (non-cases) conditions.

\section{Primary and secondary outcome}

measures Psychometric properties of the CYP-MH SAPhE instrument were evaluated through Principle Axis Factoring (PAF) with Oblimin (Kaiser normalisation) alongside measures of internal consistency (Cronbach's $\alpha$ ), convergent, discriminant and face validity.

Results PAF of the dichotomous items $(n=9)$ loaded onto three factors (1) behaviours and intentions; (2) suicidality and (3) self-harm. Factors 1 (Cronbach's $\alpha=0.960$ ) and 3 (Cronbach's $\alpha=1$ ) had high internal consistency. There was: good level of agreement between raters (kappa=0.65); a moderately positive correlation between the CYP-MH SAPhE instrument and the Columbia-Suicide Severity Rating Scale; and discrimination between cases and non-cases across the three factors (factor 1 : $m=88$ vs 70 ; factor 2 : $m=102$ vs 70 ; factor $3: m=104$ vs 68 ). Assessment of face validity resulted in six items being removed, culminating in an eight question, rapid assessment instrument.

Conclusions The results support the CYP-MH SAPhE Tool as a potentially reliable and valid instrument to identify immediate risk of self-harm in CYP presenting to acute paediatric healthcare environments, which is a burgeoning and significant global health issue.

\section{INTRODUCTION}

Self-harm in children and young people (CYP) is becoming increasingly prevalent, ${ }^{1}$ with suicide among the most common causes
Strengths and limitations of this study

- This is the first publication of a new instrument (Children and Young People-Mental Health Self-harm Assessment in Paediatric healthcare Environments, CYP-MH SAPhE Tool) to rapidly assess ( $5 \mathrm{~min})$ suicidality and self-harm of CYP that present to acute paediatric settings in mental health crisis.

- This instrument has been codeveloped with clinicians who deliver front-line care to CYP that present to acute paediatric settings in mental health crisis in order to maximise its utility.

- This instrument will contribute to the awareness, understanding and measurement of patient safety and guide interventions that may improve outcomes.

- Generalisability of the results of this study may be limited by the non-probability approach to participant selection and the homogeneity of the sample.

- Further evaluation of the CYP-MH SAPhE instrument is required across settings to confirm reliability and validity of the instrument.

of death in young people. ${ }^{2}$ Consequently, self-harm and attempted suicide are common reasons for attendance to emergency departments. ${ }^{3}$ For the purpose of this study, the term self-harm refers to the engagement in doing purposeful physical harm to one's body through either injury or poisoning, without suicidal intent. ${ }^{4}$ Importantly, self-harm is considered to serve very individual functions, for instance, alleviation or distraction from strong emotions. ${ }^{4}$ Attempted suicide is referring to the purposeful attempt to end one's life and is considered distinctly different to self-harm. However, an association has been reported between previous self-harm and future suicide attempts in young people. ${ }^{5}$

CYP presenting to emergency departments following an attempted suicide or an episode of self-harm can require immediate physical treatment. ${ }^{6}$ Following this treatment, there are often extended periods of time where 
CYP are confined to an inpatient environment and cared for by paediatric healthcare staff. In cases where immediate physical care is not required, it is not unusual for CYP to spend over 5 hours in emergency departments before receipt of specialised healthcare or assessment. ${ }^{7}$ Typically, healthcare professionals within these environments have limited mental health training, and as such, often feel ill equipped to assess and manage the associated risks apparent for CYP presenting following an episode of self-harm or attempted suicide. ${ }^{8}$ Consequently, care for self-harm within emergency departments appears to be variable, with research showing it be ineffective and delayed. ${ }^{9}$

Although, there have been recent innovations to increase the knowledge, skills and confidence in nonmental health trained healthcare professionals working with CYP within acute paediatric settings, ${ }^{10}$ there is currently no established, evidence-based instrument to assess risk. Further, as identified by Carter $e t a l,{ }^{11}$ there is a paucity of appropriate risk assessment instruments that have been psychometrically tested to assess immediate risk of self-harm and/or suicide in CYP, thus the current lack of recommendation within most current clinical guidance is likely appropriate. That being said, considering the following: (1) there is no evidence of iatrogenic effects from assessing for risk of self-harm or suicide in $\mathrm{CYP} ;{ }^{12}$ (2) there is a paucity of mental health training for emergency department and acute paediatric inpatient workforce and (3) many CYP admitted to acute hospital settings following self-harm or attempted suicide may present as immediate risk to themselves, the need for a valid and reliable instrument for use by paediatric health professionals appears high.

The aim of this study was to develop and undertake an exploratory evaluation of the psychometric properties of an instrument assessing immediate risk of suicide and self-harm in CYP presenting to acute paediatric inpatient settings.

\section{METHODS}

\section{Instrument development}

Initially, a scoping review was undertaken by the study team $^{11}$ whereby 14 assessments of self-harm and/or suicide risk in CYP that the team were able to access, and that had been subject to some form of reliability and/ or validity testing were included. These included: Adolescent Suicide Questionnaire; ${ }^{13}$ Child suicide potential scale; ${ }^{14}$ Columbia Suicide Screen; ${ }^{15}$ Columbia Suicide Severity Rating Scale (C-SSRS); ${ }^{16}$ Multi-Attitude Suicide Tendency scale; ${ }^{17}$ Reasons for living inventory for adolescents; ${ }^{18}$ Risk of Suicide Questionnaire; ${ }^{19}$ Modified Scale for Suicide Ideation; ${ }^{20}$ Suicidal Behaviours Questionnaire for Children; ${ }^{21}$ Suicidal Ideation Questionnaire; ${ }^{22}$ Suicidal ideation questionnaire-junior; ${ }^{23}$ Suicide Intent Scale $;^{24}$ Suicide Probability Scale ${ }^{25}$ and Fairy Tales Test. ${ }^{26}$ The individual items from each of the 14 instruments were extracted and reviewed via a Delphi process by 30

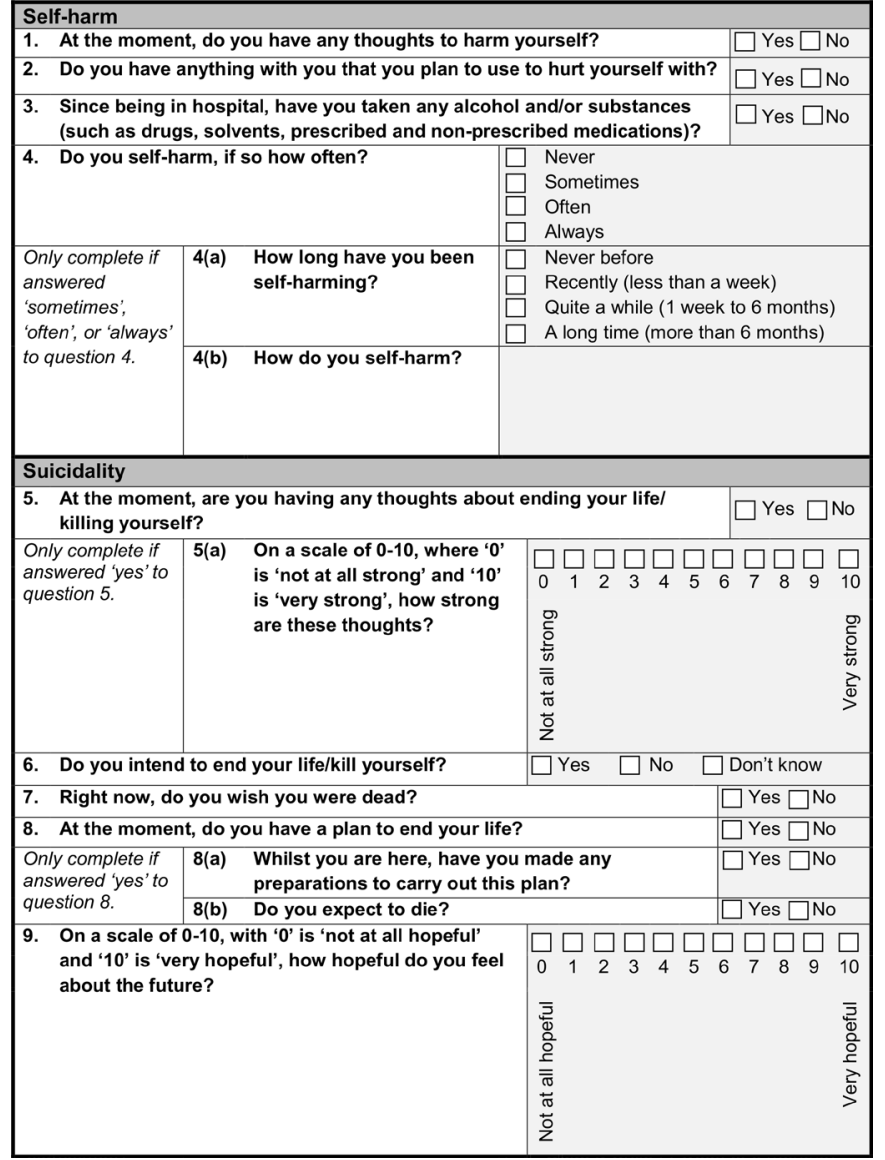

Figure 1 A14-item CYP-MH SAPhE Instrument. CYP-MH SAPhE, Children and Young People-Mental Health Self-harm Assessment in Paediatric healthcare Environments.

experts from clinical practice and academia. Following three Delphi rounds, consensus was gained on 10 suicide risk items.

A nominal group technique (NGT) meeting was then undertaken with six field experts from clinical practice. Face validity was agreed with nine self-harm items included from Delphi rounds 2 and 3. Through the NGT process, 5 out of the 19 items were removed (three were duplicates and two would likely have been assessed through routine physical care treatment). The final 14-items achieved unanimous agreement from the six participants for phrasing, ordering and scaling (figure 1).

\section{Sample and procedures}

A multicentre cohort study was conducted to examine the validity and reliability of the developed instrument (the CYP-Mental Health Self-harm Assessment in Paediatric healthcare Environments CYP-MH SAPhE) in CYP (aged 10-19 years) admitted to acute paediatric healthcare settings. Study sites were located in England and included (1) two Children's Hospitals located within large tertiary university teaching hospitals and (2) a children's service at an acute general district hospital. A detailed account of methods and procedure has been previously outlined by Manning et al. ${ }^{27}$ 


\section{Inclusion criteria}

1. Aged $10-19$ years.

2. 'Cases' who presented to acute paediatric hospital setting in mental health crisis(defined as: having reached 'breaking point', likely to harm themselves or others and behaviours that feel out of control, including extreme anxiety or panic attacks; psychotic episodes; hypomania or mania and acts of suicide or self-harm).

3. 'Non-cases' presenting to acute paediatric setting not in mental health crisis but with a primary physical medical illness or injury(defined as a health problem having physical origins, which can be short-term (accidental injury, influenza, migraine, infections) or long term (eg, diabetes, asthma, arthritis)).

\section{Exclusion criteria}

\section{Unable to speak or comprehend English} language.

2. Currently receiving active end of life care.

3. Considered too medically ill by clinicians.
A purposive sample of CYP were recruited from emergency departments and paediatric inpatient wards at three acute hospitals between October 2017 and April 2018. Participants were selected using a pre-determined eligibility criteria outlined in table 1.

Recruitment was performed by registered clinical staff and research nurses. Following an informed consent procedure, data were collected by registered clinical staff. Demographics and presenting information (date of birth; gender; ethnicity; recruitment site, hospital number; primary reason for presentation to hospital (International Classification of Diseases (ICD)-10 categories); previous hospital presentations for mental health crisis (within last 6 months); and treating physician contact details, were collected from all participants. The CYP-MH SAPhE instrument and the C-SSRS were administered to participants defined as 'cases'. 'Non-cases' only completed the CYP-MH SAPhE instrument. Data were entered into a secure, password protected, study management database and checked prior to conduct of any analyses.

Sample size calculations indicated 4-10 participants per scale item, with a minimum of 100 subjects. ${ }^{28}$ The draft instrument included 14 scale items. Therefore, we aimed to recruit between 100 (as this is the minimum number) to 140 CYP in total (50-70 cases and 50-70 non-xases).

\section{Additional measures}

The C-SSRS is a clinician rated, 19-item, measure of suicide risk. ${ }^{29}$ Considered the current gold-standard assessment for suicide risk, the C-SSRS has good predictive validity, discriminant validity, convergent validity, and sensitivity and specificity. ${ }^{29}$ The C-SSRS was completed with 'cases' only to enable assessment of the level of agreement (convergent validity) with the CYP-MH SAPhE. This was because it was deemed inappropriate to ask nonclinical cases the questions subsumed within the C-SSRS on hospital admission due to their sensitive nature.

\section{Data analysis}

Data were analysed using the latest available version of IBM SPSS V.24. Counts and percentages were calculated for dichotomous and categorical variables and descriptive statistics for continuous variables. Analysis was conducted to establish any differences between groups (cases and non-cases) and sample characteristics of age, sex and setting using independent t-test (age) or McNemars Test (sex and setting). The Mann-Whitney $U$ test was used to establish differences between cases and non-cases for CYP-MH SAPhE instrument dichotomous item responses. Values of $95 \%$ CIs were calculated and where appropriate, statistical significance was reported with the threshold of 0.05 .

All participants were included in the final analysis with any missing data handled using list wise deletion as imputation was not suitable for C-SSRS.

A standard psychometric approach was taken to explore the psychometric properties of the CYP-MH SAPhE instrument. The Factor structure was analysed using Principal Axis Factoring (PAF) with Oblimin (Kaiser Normalisation). The 14-item instrument included both Likert and dichotomous item responses, some of the items were contingent on the answers to other items, and one was qualitative. As such the instrument as a whole did not lend itself to meaningful Factor analysis and the dichotomous and Likert scale items were explored separately. Internal consistency was analysed using Cronbach's $\alpha$. Congruent validity was determined via Spearman's r correlation for non-parametric data. Discriminant validity was explored via Mann-Whitney $U$ test. Finally face validity was established through expert panel review, which was composed of expert clinicians and academics.

\section{Patient and public involvement}

The inception and design of this study was informed through meaningful engagement with patient, public and expert professionals. CYP, their parents and carers, and professionals from both acute paediatric care and child and adolescent mental health services have informed the topic and focus of the study through previous stakeholder engagement led by JCM and funded by National Health Service (NHS) England. In the development of this study, we have involved CYP to inform the focus, design and development of study information such as the participant information sheets. In addition, a group of clinical and research experts were assembled to steer the direction of this study. This included staff members who provide care for CYP experiencing mental health problems and crisis 
events on a daily basis in a range of settings that include NHS, Local Government and charity organisations.

\section{RESULTS}

\section{Participants}

In total, 163 CYP met the eligibility criteria and were recruited into the study. The sample characteristics are summarised in table 2.

The mean age of the total sample was 14.3 years (SD $1.8)$, with most of the participants being female (66.3\%), and of white British/Irish ethnicity $(87.1 \%)$. Approximately half of the sample were located within an inpatient ward setting at the time of data collection (57.7\%). Most of the sample had not experienced a previous episode of mental health crisis that warranted admission to inpatient care or attendance to ED (84\%). The sample consisted of 62 'cases' and 101 'non-cases', with analysis showing no statistically significance differences between groups in relation to age ( $\mathrm{t}=1.439$; mean difference $.422 ; 95 \%$ CI -0.157 to 1.002 ), sex (Asymp. $\mathrm{p}=0.396$ ) or setting (Asymp. $\mathrm{p}=0.483$ ).

\section{Overview of instrument responses}

A summary of participant responses to the CYP-MH $\mathrm{SAPhE}$ instrument and the C-SSRS are presented in the tables 3-5). Specifically, table 3 presents responses to the dichotomous items and table 3 compares the responses to the Likert items of the CYP-MH SAPhE instrument for both cases and non-cases. Table 5 presents counts and percentages for Suicidal Ideation, Suicidal Behaviour and Self Injurious Behaviour without Suicidal Intent Based on the C-SSRS items from cases only.

\section{Factor analysis}

Analysis of Likert Items for self-harm and Suicide

The four Likert scale items included in the instrument were narrated as two Factors, one being self-harm and one suicidality. We wanted to determine that these were indeed two discrete Factors with a view to identifying self-harm and suicidality as two separate risk assessments that form together a battery of assessment. We therefore explored the suitability of these items for Factor analysis. A total score was computed as the sum of ratings across all four Likert scale items. Individual items were correlated with the sum total of the scale and were excluded where $\mathrm{r}<0.3 .^{30}$ No items were excluded from further analysis leaving the four items for inclusion in the Factor analysis. PAF with Oblimin (Kaiser normalisation) rotation was conducted on the four items. The Kaiser-Meyer Olkin (KMO) measure of sampling adequacy suggested that the sample was not Factorable $(\mathrm{KMO}=0.584)$. Although Bartlett's Test of Sphericity was highly significant $\left(\chi^{2}=505\right.$, $\mathrm{df}=6, \mathrm{p}<0.001)$, high off-diagonal values in the anti-image correlation matrix suggested that the data were not suitable for factor analysis. ${ }^{31}$

Analysis of dichotomous items for self-harm and suicide

The nine dichotomous scale items included in the instrument were explored for their suitability for Factor

\begin{tabular}{|c|c|c|c|}
\hline Characteristic & $\begin{array}{l}\text { Case } \\
(\mathrm{N}=62)\end{array}$ & $\begin{array}{l}\text { Non-case } \\
(\mathrm{N}=101)\end{array}$ & $\begin{array}{l}\text { Total } \\
\text { sample }\end{array}$ \\
\hline $\begin{array}{l}\text { Age (years); mean } \\
\text { (SD) }\end{array}$ & $14.6(1.7)$ & $14.2(1.9)$ & $14.3(1.8)$ \\
\hline \multicolumn{4}{|l|}{ Gender; n (\%) } \\
\hline Male & $13(21.3)$ & $41(39.2)$ & $54(32.5)$ \\
\hline Female & $49(78.7)$ & 59 (59.8) & $108(66.3)$ \\
\hline MD & - & $1(1)$ & $1(1.2)$ \\
\hline \multicolumn{4}{|l|}{ Ethnicity; n (\%) } \\
\hline African & - & $3(2.9)$ & $3(1.8)$ \\
\hline British/African & - & $1(1.0)$ & $1(0.6)$ \\
\hline British/Pakistani & $1(1.6)$ & - & $1(0.6)$ \\
\hline Chinese & - & $2(2.0)$ & $2(1.2)$ \\
\hline Indian & $1(1.6)$ & $1(1.0)$ & $2(1.2)$ \\
\hline Middle-Eastern & $1(1.6)$ & - & $1(0.6)$ \\
\hline Mixed Race & $2(3.3)$ & $2(2.0)$ & $4(2.5)$ \\
\hline Pakistani & - & $3(2.9)$ & $3(1.8)$ \\
\hline White British/lrish & 57 (91.8) & $86(84.3)$ & $142(87.1)$ \\
\hline Other & - & $3(2.9)$ & $3(1.8)$ \\
\hline MD & - & $1(1.0)$ & $1(0.6)$ \\
\hline \multicolumn{4}{|l|}{ Setting; n (\%) } \\
\hline Inpatient ward & $33(54.1)$ & $62(60.1)$ & $94(57.7)$ \\
\hline $\begin{array}{l}\text { Emergency } \\
\text { department }\end{array}$ & $29(45.9)$ & $40(39.9)$ & $69(42.3)$ \\
\hline \multicolumn{4}{|l|}{$\begin{array}{l}\text { Previous mental } \\
\text { health crisis; }{ }^{*} \mathrm{n}(\%)\end{array}$} \\
\hline Yes & $19(31.1)$ & $1(2.0)$ & $20(12.3)$ \\
\hline No & $42(67.2)$ & $95(94.1)$ & $137(84)$ \\
\hline MD & $1(1.7)$ & $4(3.9)$ & $1(0.6)$ \\
\hline \multicolumn{4}{|l|}{$\begin{array}{l}\text { Primary } \\
\text { presentation;† n (\%) }\end{array}$} \\
\hline Suicide attempt & $37(60.6)$ & - & - \\
\hline Suicidal thoughts & $4(6.6)$ & & \\
\hline $\begin{array}{l}\text { Self-harm } \\
\text { behaviour }\end{array}$ & $9(14.7)$ & & \\
\hline $\begin{array}{l}\text { Depression/low } \\
\text { mood }\end{array}$ & $4(6.6)$ & & \\
\hline Eating disorder & $5(8.2)$ & & \\
\hline Substance misuse & $2(3.3)$ & & \\
\hline
\end{tabular}

${ }^{*}$ Previous 6-month period.

†Mental health crisis data presented for cases only. $\mathrm{MD}$, missing data.

analysis. A total score was computed as the sum of ratings across all nine dichotomous items. Individual items were correlated with the sum total of the scale. Point biserial correlations were excluded where $r<0.3{ }^{32}$ As a result no items were excluded from further analysis.

PAF with Oblimin (Kaiser normalisation) rotation was conducted on the nine items. The KMO measure of 
Table 3 Summary of dichotomous item responses from cases and non-cases to the CYP-MH SAPhE instrument

\begin{tabular}{|c|c|c|c|c|c|c|}
\hline \multirow[b]{2}{*}{ Dichotomous item } & \multicolumn{3}{|c|}{$\begin{array}{l}\text { Cases }(\mathrm{N}=62) \\
\text { Count (\% of group) }\end{array}$} & \multicolumn{3}{|c|}{$\begin{array}{l}\text { Non-cases }(\mathrm{N}=101) \\
\text { Count (\% of group) }\end{array}$} \\
\hline & Yes & No & MD & Yes & No & MD \\
\hline $\begin{array}{l}\text { 2. Do you have anything with you that you plan to use to } \\
\text { hurt yourself with? }\end{array}$ & $3(4.8)$ & $59(95.2)$ & $0(0)$ & $0(0)$ & $101(100)$ & $0(0)$ \\
\hline $\begin{array}{l}\text { 5. At the moment, are you having any thoughts about } \\
\text { ending your life/ killing yourself? }\end{array}$ & $29(46.8)$ & $33(53.2)$ & $0(0)$ & $0(0)$ & $101(100)$ & $0(0)$ \\
\hline 6. Do you intend to end your life/kill yourself? & $19(30.6)$ & $37(59.7)$ & $6(9.7)$ & $1(1.0)$ & $100(99.0)$ & $0(0)$ \\
\hline $\begin{array}{l}\text { 8b. While you are here, do you expect to die from this } \\
\text { plan? }\end{array}$ & $3(4.8)$ & $59(95.2)$ & $0(0)$ & $0(0)$ & $101(100)$ & $0(0)$ \\
\hline
\end{tabular}

CYP-MH SAPhE, Children and Young People-Mental Health Self-harm Assessment in Paediatric healthcare Environments; MD, missing data.

sampling adequacy suggested that the sample was Factorable $(\mathrm{KMO}=0.719)$. Bartlett's test of sphericity was highly significant $\left(\chi^{2}=5352, \mathrm{df}=36, \mathrm{p}<0.001\right)$, low off-diagonal values in the anti-image correlation matrix suggested that the data were suitable for factor analysis. ${ }^{31}$ Observation of the scree plot indicated a parsimonious three factorial structure explaining $93 \%$ of total variance.

The pattern matrix was used for interpretation (table 6). No items were excluded as they all met the Comrey and Lee $^{33}$ 'fair' threshold for Factor loading criterion on 0.45 and no cross-loadings were observed. Based on these criteria, five items loaded on to factor 1 . These items related to behaviours and intentions. Two items loaded on to factor 2 . These items were related to suicidality and two items loaded onto factor 3 . These items related to self-harm.

\section{Reliability}

Items in factor 1 demonstrated high reliability (Cronbach's $\alpha=0.960)$, items in factor 2 demonstrated poor reliability (Cronbach's $\alpha=0.456$ ) and items in factor 3 demonstrated high reliability (Cronbach's $\alpha=1$ ). Interrater analysis demonstrated a significantly significant and good level of agreement between raters (kappa $=0.65$, $\mathrm{p}<0.001)$.

\section{Congruent validity}

We hypothesised that the CYP-MH SAPhE instrument would positively correlate with The C-SSRS. We found a statistically significant (two tailed) moderate positive correlation between the two instruments $(\mathrm{rs}=0.438$, $\mathrm{p}=0.001$ ). The CYP-MH SAPhE instrument seeks to measure risk of both self-harm and suicide whist the
C-SSRS is a measure of suicidal ideation and behaviour only. This moderate correlation would suggest that the CYP-MH SAPhE instrument is correlating on the suicidal ideation and behavioural aspects of the C-SSRS but is also capturing another dimension (self-harm) and therefore diverges with the C-SSRS as well.

\section{Discriminant/divergent validity}

We hypothesised that there would be a significant difference between the mean scores of cases presenting with $\mathrm{MH}$ crisis and non-cases, presenting at services not in $\mathrm{MH}$ crisis. Mann-Whitney U test indicated that the mean score for the Likert scale items was significantly greater in cases $(\mathrm{m}=88)$ than in non-cases $(\mathrm{m}=70), \mathrm{U}=2416, \mathrm{p}=0.020$.

Factor 1: Mann-Whitney $U$ test indicated that the mean score for Factor 1 was significantly greater in cases $(\mathrm{m}=102)$ than in non-cases $(\mathrm{m}=70), \mathrm{U}=1882, \mathrm{p}<0.001$. Factor 2: Mann-Whitney U test indicated that there was a small but significant differences between mean scores of cases $(\mathrm{m}=86)$ and non-cases $(\mathrm{m}=74), \mathrm{U}=2649, \mathrm{p}=0.048$. Factor 3: Mann-Whitney $\mathrm{U}$ test indicated that the mean score for factor 3 was significantly greater in cases of crisis $(\mathrm{m}=104)$ than in non-cases $(\mathrm{m}=68), \mathrm{U}=1739, \mathrm{p}<0.001$.

\section{Face validity}

Evaluation of the application of the instrument led to questions 3, 4, 5a and 9 being removed from, and a 'don't know' box being added to question 7 . The remaining questions 5 and 6 that ended with the terminology 'end your life/kill yourself' were restricted to just an 'end your life'. The instrument was also colour coded for scoring purposes using a green-red flagging system. The expert 


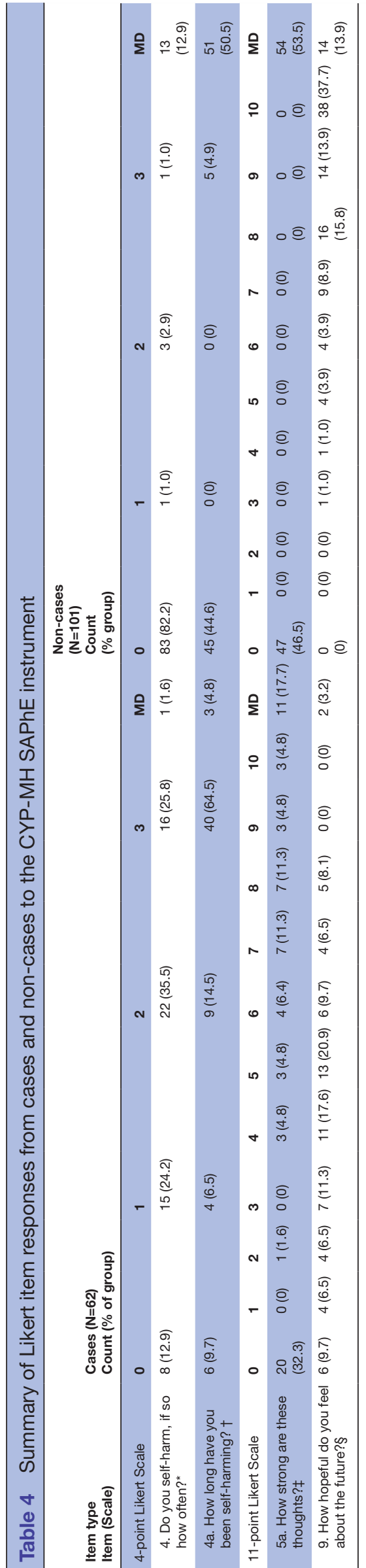

Table 5 Number of cases with suicidal ideation, suicidal behaviour and self injurious behaviour without suicidal intent based on the C-SSRS items

\begin{tabular}{ll}
\hline $\begin{array}{l}\text { C-SSRS constructs/items with } \\
\text { dichotomous responses }\end{array}$ & $\begin{array}{l}\text { Cases (N=62) } \\
\text { n (\%) }\end{array}$ \\
\hline $\begin{array}{l}\text { Suicidal Ideation (at least one 'yes' } \\
\text { response to items) }\end{array}$ & $53(85.5)$ \\
\hline $\begin{array}{l}\text { Wish to be dead } \\
\text { Non-specific active suicidal thoughts }\end{array}$ & $49(79.0)$ \\
\hline $\begin{array}{l}\text { Active suicidal ideation with any methods } \\
\text { (not plan) without intent to act }\end{array}$ & $39(62.9)$ \\
\hline $\begin{array}{l}\text { Active suicidal ideation with some intent } \\
\text { to act, without specific plan }\end{array}$ & $38(61.3)$ \\
\hline $\begin{array}{l}\text { Active suicidal ideation with specific plan } \\
\text { and intent }\end{array}$ & $21(33.9)$ \\
\hline $\begin{array}{l}\text { Suicidal behaviour (at least one 'yes' } \\
\text { response to items) }\end{array}$ & $56(90.3)$ \\
\hline $\begin{array}{l}\text { Actual attempt (non-fatal) } \\
\text { Interrupted attempt }\end{array}$ & $48(77.4)$ \\
\hline $\begin{array}{l}\text { Aborted or self-interrupted attempt } \\
\text { Preparatory acts or behaviour }\end{array}$ & $29(46.8)$ \\
\hline $\begin{array}{l}\text { Suicidal behaviour } \\
\text { Engaged in non-suicidal self-injurious } \\
\text { behaviour }\end{array}$ & $43(69.4)$ \\
\hline
\end{tabular}

C-SSRS, Columbia-Suicide Severity Rating Scale.

panel subsequently reviewed and agreed these changes that culminated in the final instrument (figure 2).

\section{DISCUSSION}

Prior to this study, there was no established, psychometrically tested instrument to assess immediate risk of selfharm and suicide in CYP presenting to acute paediatric healthcare within emergency departments and inpatient settings. Thus, limiting the ability of non-mental health trained staff working in these areas to effectively and systematically assess risk and support safety management decisions for CYP presenting in mental health crisis.

Through a thorough scope of the existing literature ${ }^{34}$ and subsequent collaboration with an expert panel of academics and clinicians, an instrument was developed to assess immediate risk of suicide and/or self-harm in CYP presenting in mental health crisis to acute paediatric hospital settings and emergency departments.

Testing of the instrument across three acute hospital sites (Paediatric Emergency Departments and Acute Paediatric Wards) within the UK resulted in an eight-item instrument, weighted into two constructs (self-harm and suicidality) being developed. The results demonstrate that the CYP-MH SAPhE instrument is reliable, with high levels of internal consistency across the two constructs and high levels of inter-rater reliability. The instrument demonstrated high levels of congruent validity with a 


\begin{tabular}{|c|c|c|c|}
\hline \multirow[b]{2}{*}{ Questions } & \multicolumn{3}{|l|}{ Factor } \\
\hline & $\begin{array}{l}\text { 1: Behaviours } \\
\text { and intentions }\end{array}$ & 2: Suicidality & 3: Self-harm \\
\hline $\begin{array}{l}\text { Q5. At the moment, are you having any thoughts about ending your } \\
\text { life/ killing yourself? }\end{array}$ & 0.993 & & \\
\hline $\begin{array}{l}\text { Q3. Since being in hospital, have you taken any alcohol and/or } \\
\text { substances (such as drugs, solvents, prescribed and non-prescribed } \\
\text { medications)? }\end{array}$ & 0.993 & & \\
\hline Q8. At the moment, do you have a plan to end your life? & 0.954 & & \\
\hline Q7. Right now, do you wish you were dead? & 0.932 & & \\
\hline Q6. Do you intend to end your life/kill yourself? & 0.722 & & \\
\hline Q8b. While you are here, do you expect to die from this plan? & & 0.992 & \\
\hline $\begin{array}{l}\text { Q8a. While you are here, have you made any preparations to carry } \\
\text { out this plan? }\end{array}$ & & 0.991 & \\
\hline Q1. At the moment, do you have any thoughts to harm yourself? & & & 0.999 \\
\hline $\begin{array}{l}\text { Q2. Do you have anything with you that you plan to use to hurt } \\
\text { yourself with? }\end{array}$ & & & 0.999 \\
\hline
\end{tabular}

*It is important to note that Factor analysis of dichotomous variables may lead to the endorsement of strong items rather than picking up on underlying latent variables so should be taken as guidance only and with caution.

previously developed in-depth instrument designed to assess suicide risk, and high levels of discriminant validity suggesting it is able to adequately discriminate between CYP presenting with a primary mental health crisis and those CYP presenting to acute paediatric setting with a primary physical medical illness or injury. The instrument
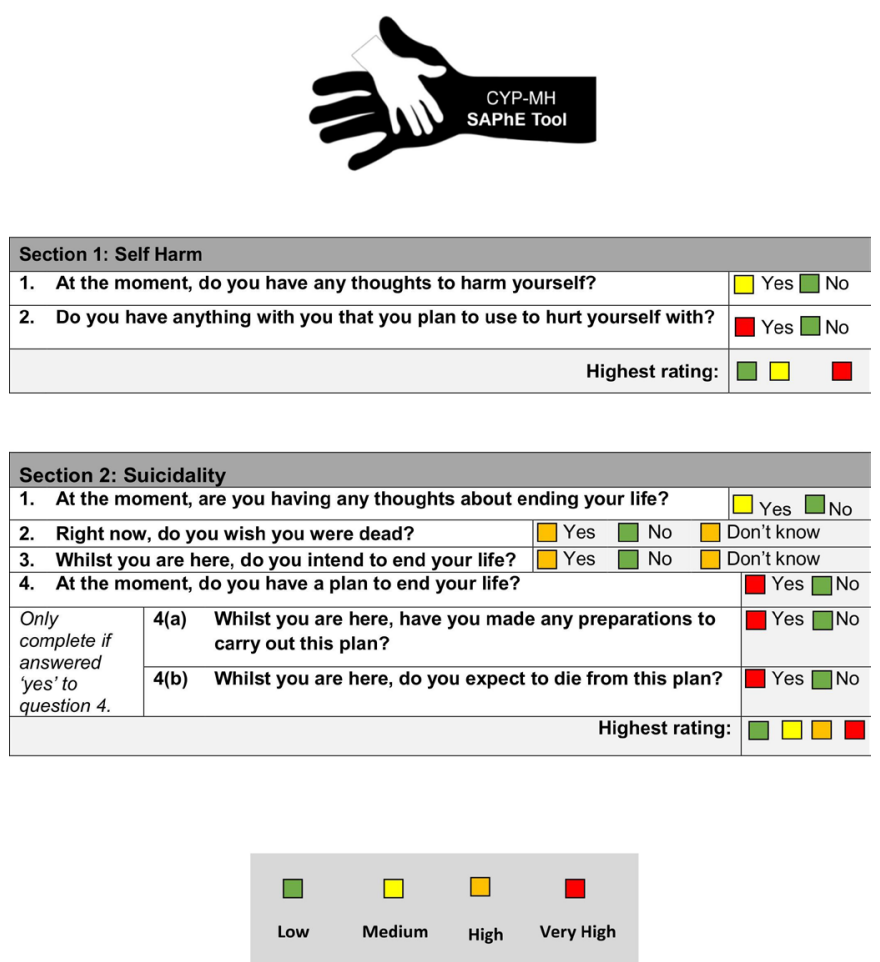

Figure 2 Final CYP-MH SAPhE Instrument . ${ }^{27}$ CYP-MH SAPhE, Children and Young People-Mental Health Self-harm Assessment in Paediatric healthcare Environments. was also face valid in that it was acceptable and understandable to CYP evident from the minimal amount of missing data.

This study has several limitations that must be noted. First, the Likert scale data were not suitable for factor analysis. There are several reasons why this may be the case, for example, with a more robust sample size sample adequacy may have been reached. However, the instrument as it stands was derived using both a top down and bottom up process that through the Delphi method, developed iteratively into self-harm and suicide facets. Considering the robustness of our development process and the extant literature that would define self-harm and suicide as separate constructs, this appears appropriate. Future exploration of factor 2 'Suicidality' is required to determine the robustness of this Factor as within this current sample it demonstrated poor reliability. It may be that the 'planning' aspects of suicidality are not as suitable to Factor analysis as they represent events that are yet to come or, it may be that within our sample, not enough participants were in this planning state for us to accurately explore this Factor. Moreover, it should be acknowledged that while the psychometric item evaluation allows us to better understand the relationships between variables, the strength of the scale lies in its codevelopment by those in clinical practice for application within a clinical practice setting. Second, generalisability of the results of this study may be limited by the non-probability approach to participant selection and the homogeneity of the sample which included predominantly female CYP, with white British ethnicity. Third, it should be noted that in some instances inter-rater assessments were made up to 4 hours apart. This may have influenced agreement as this time 
lapse in the assessment may well see notable changes in clinical presentation. Fourth, non-cases did not complete the C-SSRS. Therefore, we are unable to establish convergent validity with the CYP-MH SAPhE instrument in those with a non-mental health-related primary presentation. Collectively, these limitations need to be comprehended and mitigated in future evaluative work relating to the CYP-MH SAPhE instrument.

Despite these recognised limitations, this study has revealed that the CYP-MH SAPhE instrument is a rapid and sensitive instrument to identify immediate risk of self-harm and suicidality in CYP (aged 10-19 years) presenting to acute paediatric care. The CYP-MH SAPhE Tool has potential utility as a screener by the paediatric health professional in the inpatient ward or emergency department as part of their holistic assessment of the CYP. Due to the increasing global prevalence of young people presenting to acute paediatric settings in acute mental health crisis, the CYP-MH SAPhE instrument now requires further evaluation to confirm its suitability and effectiveness in clinical practice.

\section{Author affiliations}

${ }^{1}$ Children and Young People Health Research, School of Health Sciences, University of Nottingham, Nottingham, UK

${ }^{2}$ Nottingham Children's Hospital, Nottingham University Hospitals NHS Trust, Nottingham, UK

${ }^{3} \mathrm{NUH}$ Institute of Nursing and Midwifery Care Excellence, Nottingham University Hospitals NHS Trust, Nottingham, UK

${ }^{4}$ School of Health Sciences, University of Nottingham, Nottingham, UK

\section{Twitter Joseph C Manning @josephcmanning}

Acknowledgements We would like to acknowledge:(i) The CYP-MH SAT Study Group consisting of: (1) The study steering group: Dorothy Bean, Marie Armstrong, Rebecca Green, Sharon O'Love, David Clark, Rachel Dolby, Elizabeth Byrne, Dr Damian Wood, Tessa Jones; (2) The site principal investigators: Rachel Barker, Miranda Witchell, Dr Lynda Walton; Dr Gisela Robinson; (3) The research delivery staff: Melanie Hayman, Coral Smith, Vanessa Unsworth, Caroline Moulds and Laura Looby. (ii) Dr Malcolm Schofield (Lecturer in Psychology, University of Derby) for support with the psychometric analysis.

Collaborators Dorothy Bean; Marie Armstrong; Rebecca Green; Sharon O'Love; David Clark; Rachel Dolby; Elizabeth Byrne; Damian Wood; Tessa Jones; Rachel Barker; Miranda Witchell; Lynda Walton; Gisela Robinson; Melanie Hayman; Coral Smith; Vanessa Unsworth; Caroline Moulds; Laura Looby.

Contributors JCM was the chief investigator and lead for the study. JCM, TC, GW, JC, AA and CYP-MH SAT Study Group contributed to the study design. GW, TC, JCM and CYP-MH SAT Study Group undertook the data collection with the participation of the study sites. AA, JCM and TC conducted the data analysis. JCM, TC, GW, JC and AA contributed to drafting the manuscript. JCM, TC, GW, JC, AA and the CYPMH SAT Study Group agreed the final manuscript for publication, and agree to be accountable for all aspects of the work.

Funding This study was funded through a research grant from Nottingham City Clinical Commissioning Group who were not involved in the study design, collection, analysis, interpretation of the data.

Competing interests None declared.

Patient consent for publication Not required.

Ethics approval Approvals were obtained from a UK Health Research Authority (Trent Research Ethics Committee- Derby 1: 17/EM/0347) and local NHS trusts (Nottingham University Hospitals NHS Trust; University Hospitals of Derby and Burton NHS Foundation Trust; Sherwood Forest Hospitals NHS Foundation Trust) prior to the collection of any data.

Provenance and peer review Not commissioned; externally peer reviewed.
Data availability statement Data are available on reasonable request. The full anonymised dataset is accessible on request to the corresponding author. The CYP-MH SAPhE Instrument is availible for use (free of charge) on written request to the corresponding author.

Open access This is an open access article distributed in accordance with the Creative Commons Attribution Non Commercial (CC BY-NC 4.0) license, which permits others to distribute, remix, adapt, build upon this work non-commercially, and license their derivative works on different terms, provided the original work is properly cited, appropriate credit is given, any changes made indicated, and the use is non-commercial. See: http://creativecommons.org/licenses/by-nc/4.0/.

ORCID iD

Joseph C Manning http://orcid.org/0000-0002-6077-4169

\section{REFERENCES}

1 Morgan C, Webb RT, Carr MJ, et al. Incidence, clinical management, and mortality risk following self harm among children and adolescents: cohort study in primary care. BMJ 2017;359:j4351.

2 World Health Organisation. Suicide data. Available: https://www.who. int/mental_health/prevention/suicide/suicideprevent/en/

3 Parsonage M, Fossey M, Tutty C. Liason psychiatry in the modern NHS. London: Centre for Mental Health, 2012.

4 King J, Cabarkapa S, Leow F. Adolescent self-harm: think before prescribing. Aust Prescr 2019;42:90-2.

5 Castellví P, Lucas-Romero E, Miranda-Mendizábal A, et al. Longitudinal association between self-injurious thoughts and behaviors and suicidal behavior in adolescents and young adults: a systematic review with meta-analysis. J Affect Disord 2017;215:37-48.

6 Renaud J, Berlim MT, Séguin M, et al. Recent and lifetime utilization of health care services by children and adolescent suicide victims: a case-control study. J Affect Disord 2009;117:168-73.

7 Grupp-Phelan J, Mahajan P, Foltin GL, et al. Referral and resource use patterns for psychiatric-related visits to pediatric emergency departments. Pediatr Emerg Care 2009;25:217-20.

8 Crawford T, Geraghty W, Street K, et al. Staff knowledge and attitudes towards deliberate self-harm in adolescents. J Adolesc 2003;26:619-29.

9 Burns J, Dudley M, Hazell P, et al. Clinical management of deliberate self-harm in young people: the need for evidence-based approaches to reduce repetition. Aust N Z J Psychiatry 2005;39:121-8.

10 Manning JC, Carter T, Latif A, et al. 'Our care through our eyes'. impact of a co-produced digital educational programme on nurses' knowledge, confidence and attitudes in providing care for children and young people who have self-harmed: a mixed-methods study in the UK. BMJ Open 2017;7:e014750.

11 Carter T, Walker GM, Aubeeluck A, et al. A scoping review of the psychometric properties of safety management tools used to assess acute risk of suicide and/or self-harm behaviours in children and young people 2017.

12 Gould MS, Marrocco FA, Kleinman M, et al. Evaluating iatrogenic risk of youth suicide screening programs. JAMA 2005;293:1635.

13 Horowitz LM, Bridge JA, Teach SJ, et al. Ask Suicide-Screening questions (ASQ). Arch Pediatr Adolesc Med 2012;166:1170.

14 Pfeffer CR. Child suicide potential scales. In: Pfeffer CR, ed. New York: Guilford Press, 1986. : 173-203p.

15 Shaffer D, Scott M, Wilcox H, et al. The Columbia suicide screen: validity and reliability of a screen for youth suicide and depression. $J$ Am Acad Child Adolesc Psychiatry 2004;43:71-9.

16 Posner K, Brown GK, Stanley B, et al. The Columbia-Suicide severity rating scale: initial validity and internal consistency findings from three multisite studies with adolescents and adults. Am J Psychiatry 2011;168:1266-77.

17 Orbach I, Milstein I, Har-Even D, et al. A Multi-Attitude suicide tendency scale for adolescents. Psychol Assess 1991;3:398-404.

18 Osman A, Downs WR, Kopper BA, et al. The reasons for living inventory for adolescents (RFL-A): development and psychometric properties. J Clin Psychol 1998;54:1063-78.

19 Horowitz LM, Wang PS, Koocher GP, et al. Detecting suicide risk in a pediatric emergency department: development of a brief screening tool. Pediatrics 2001;107:1133-7.

20 Miller IW, Norman WH, Bishop SB, et al. The modified scale for suicidal ideation: reliability and validity. J Consult Clin Psychol 1986;54:724-5

21 Cotton CR, Range LM. Reliability and validity of the suicide intervention response inventory. Death Stud 1992;16:79-86. 
22 Reynolds WM. Suicide ideation questionnaire. Odessa, FL:

Psychological Assessment Resources, 1987.

23 Reynolds WM. Suicidal ideation questionnaire-junior. Odessa, FL: Psychological Assessment Resources, 1987: 16-18.

24 Beck AT, Schuyler D, Herman I. Development of suicidal intent scales. In: Beck AT, Resnik HLP, Lettieri DJ, eds. Oxford: Charles Press Publishers, 1974: p. 249

25 Cull JG, Gill WS. Suicide probability scale. Los Angeles, CA.: Western Psychological Services, 1982.

26 Orbach I, Carlson G, Feshbach S, et al. Attitudes toward life and death in suicidal, normal, and chronically ill children: an extended replication. J Consult Clin Psychol 1984;52:1020-7.

27 Manning JC, Walker GM, Carter T, et al. Children and young PeopleMental health safety assessment tool (CYP-MH Sat) study: protocol for the development and psychometric evaluation of an assessment tool to identify immediate risk of self-harm and suicide in children and young people (10-19 years) in acute paediatric hospital settings. BMJ Open 2018;8:e020964.
28 Terwee CB, Bot SDM, de Boer MR, et al. Quality criteria were proposed for measurement properties of health status questionnaires. J Clin Epidemiol 2007;60:34-42.

29 Posner K, Brent D, Lucas C, et al. Columbia-suicide severity rating scale (C-SSRS). New York, NY: Columbia University Medical Center, 2008.

30 Bernstein IH, Nunnally JC. A catastrophe model for developing service satisfaction strategies. Journal of Marketing 1994;56:83-95.

31 Tabachnick BG, Fidell LS, Ullman JB. Using multivariate statistics. Boston, MA: Pearson, 2007.

32 Nunnally JC, Bernstein IH. Psychological theory. New York, NY: MacGraw-Hill, 1994: 131-47.

33 Comrey A, Lee H. A first course in factor analysis. Hillsdale, NJ: Erlbaum, 1992

34 Carter T, Walker GM, Aubeeluck A. Assessment tools of immediate risk of self-harm and suicide in children and young people: a scoping review. Journal of child health care 2018. 